\title{
Structural Studies of Titanium Oxide Multilayers
}

\author{
G.P. Karwasz ${ }^{a}$, A. Miotello ${ }^{a}$, E. Zomer ${ }^{a}$, R.S. Brusa ${ }^{a}$, \\ B. Kościelska ${ }^{b}$, C. Armellini ${ }^{c}$ And A. Kuzmin ${ }^{d}$ \\ ${ }^{a}$ Dipartimento di Fisica, Università di Trento, 38050 Povo (TN), Italy \\ ${ }^{b}$ Instytut Fizyki, Politechnika Gdańska, 81-862 Gdańsk, Poland \\ ${ }^{c}$ Istituto di Fotonica e Nanotccnologie, CNR, 38050 (TN), Italy \\ ${ }^{d}$ Institute of Solid State Physics, University of Latvia, 1063 Riga, Latvia
}

(Received January 26, 2005)

\begin{abstract}
Multilayers of titanium oxide on conductive glasses (silica, covered with indium/tin and tin oxides) were obtained by different methods (from suspension, by sol-gel, by vacuum sputtering). X-ray diffraction and positron annihilation depth-resolved characterization of these samples are presented. The data allow us to determine optimal deposition parameters, in order to obtain the anatase phase, important in practical applications in photoelectrochemical cells.
\end{abstract}

PACS numbers: 82.47.Jk, 78.70.Bj, 61.10.Nz

\section{Introduction}

Titanium oxide multilayers are used in photochromic devices [1], photochemical applications [2], photoelectrochemical cells [3], and in semiconductor devices as isolating gate material [4]. Both the thickness of $\mathrm{TiO}_{2}$ layers and the exact phase (amorphous, low-temperature anatase or high-temperature rutile) are important in these applications.

In particular, $\mathrm{TiO}_{2}$ nanocrystalline anatase, covered with monolayers of organic pigments allows us to achieve as high as $10 \%$ quantum yield in photoelectrochemical solar cells [5]. In such devices, $\mathrm{TiO}_{2}$ is deposited on a glass substrate which is covered with transparent, conductive oxides, like tin-indium oxide (ITO). Recently, additional thin metallic layers separating ITO and $\mathrm{TiO}_{2}$ are used [6].

In this paper, we report structural studies of $\mathrm{TiO}_{2}$ layers deposited by different methods on glass and on glasses covered with conducting oxides. In the extended work [7], we have described different methods of deposition: (1) sol-gel, 
(2) dc magnetron sputtering, and (3) deposition from suspensions of nanocrystalline $\mathrm{TiO}_{2}$. This latter method, although giving nanocrystalline morphology of the $\mathrm{TiO}_{2}$ surface, did not produce uniform layers. Sodium glasses, sodium glasses covered with tin/indium oxides, and alumina-silicate glasses covered with tin/indium oxides were used as substrates. Layers were studied by scanning electron microscopy, photoabsorption in UV and VIS range. Compositional analysis has been carried on by electron-induced X-ray emission, positron annihilation spectroscopy, and X-ray diffraction techniques. Complex multilayers were used as photocathodes in photoelectrochemical cells.

The optimal mode of preparing these mutlilayers, in order to achieve both high quantum yield of photoemission and assure a high efficiency of the charge transfer to underlying conducting layer, remains an open question. To our knowledge, the possible presence of charge trapping defects between layers has not been studied yet.

\section{Samples}

The main method used was the sol-gel deposition. A starting solution to obtain $\mathrm{TiO}_{2}$ films was prepared by mixing titanium butoxide with ethanol (EtOH) in a molar ratio 1:5 and acetyloacetone (AcAc) as the complexing agent. The films were deposited by a spin-off coating technique. The resulting gel layers were dried and then heated at a chosen temperature (from $300^{\circ} \mathrm{C}$ to $700^{\circ} \mathrm{C}$, as specified) for 1 hour in air (with a 5 hour temperature rise ramp) in order to obtain smooth homogeneous films. By repeating the above procedure we obtained double and triple layers; the thickness of a single deposition was about $150 \mathrm{~nm}$.

As substrates sodium-silica glass (a typical composition is $72.6 \% \mathrm{SiO}_{2}$, $\left.15.2 \% \mathrm{Na}_{2} \mathrm{O}, 0.8 \% \mathrm{~B}_{2} \mathrm{O}_{3}, 1.7 \% \mathrm{Al}_{2} \mathrm{O}_{3}, 4.6 \% \mathrm{CaO}, 3.6 \% \mathrm{MgO}\right)$ and alumina-silica glass $\left(55.0 \% \mathrm{SiO}_{2}, 7.0 \% \mathrm{~B}_{2} \mathrm{O}_{3}, 10.4 \% \mathrm{Al}_{2} \mathrm{O}_{3}, 21 \% \mathrm{CaO}, 1.0 \% \mathrm{Na}_{2} \mathrm{O}\right)$ of $1.1 \mathrm{~mm}$ thickness were used. These glasses, already covered with ITO layers (150-300 A for $\mathrm{Na}-\mathrm{Si}$ glasses, $1200-1600 \AA$ for Al-Si glasses) were obtained from Sigma-Aldrich. In Na-Si glasses a barrier coating of $\mathrm{SiO}_{2} 200-300 \AA$ thick is placed between the glass and the ITO layer.

In the case of $\mathrm{TiO}_{2}$ films, obtained by dc magnetron sputtering, the sodium silicate glass substrates without ITO layer were used. The sputtering was performed from metallic Ti target in a mixed $\mathrm{Ar} / \mathrm{O}_{2}$ atmosphere with $\mathrm{O}_{2}$ contents of about $24-38 \%$. The substrates were located at about $8 \mathrm{~cm}$ above the target. Deposition times were 60 and 120 minutes, with $140 \mathrm{~W}$ magnetron power applied.

\section{Techniques}

Structural phase analysis was performed by X-ray diffraction (XRD) technique using a PANalytical X'Pert PRO diffractometer. Conventional X-ray tube with $\mathrm{Cu}$ anode, operated at $45 \mathrm{kV}$ and $40 \mathrm{~mA}$, was used as an X-ray source. 
The use of a variable-energy positron beam allows us to study depth-resolved profiles of the material down to a few micrometer deep layers [8]. A slow positron beam with an energy variable between $50 \mathrm{eV}$ and $25 \mathrm{keV}$ was obtained by moderating positrons from a $30 \mathrm{mCi}{ }^{22} \mathrm{NaCl}$ radioactive source in a $1 \mu \mathrm{m}$ thick singlecrystal tungsten foil. Details about apparatus and the measurement techniques are reported in Ref. [9].

The shape of the $511 \mathrm{keV}$ annihilation line has been characterized by the $S$-parameter, calculated as the ratio of the counts in the central area of the peak $\left|511.0-E_{\gamma}\right| \leq 0.85$ (in $\mathrm{keV}$ ) and the total area of the peak $\left|511.0-E_{\gamma}\right| \leq 4.25$ (in $\mathrm{keV}$ ). It has been normalized to the $S$-value in a defect-free, high-purity silicon (the positron lifetime measured in such a sample was $220 \mathrm{ps}$ ).

The Doppler shape parameter was measured as a function of the positron implantation energy. The implantation depth (in $\AA$ ) can be obtained from positron energy using the formula: $d=(400 / \rho) E^{1.6}$ with $E$ being the beam energy and $\rho$ - the layer density. However, exact densities of the layers are not known. The densities for bulk materials would be $3.84 \mathrm{~g} / \mathrm{cm}^{3}$ for anatase, $4.26 \mathrm{~g} / \mathrm{cm}^{3}$ for rutile, $6.95 \mathrm{~g} / \mathrm{cm}^{3}$ for $\mathrm{SnO}_{2}, 7.18 \mathrm{~g} / \mathrm{cm}^{3}$ for $\mathrm{In}_{2} \mathrm{O}_{3}$. In reference to Fig. 4a, the positron mean range at $7.5 \mathrm{keV}$ implantation energy would be $1400 \AA$ for the density of $7 \mathrm{~g} / \mathrm{cm}^{3}$; in reference to Fig. $4 \mathrm{~b}$, for the density of $4 \mathrm{~g} / \mathrm{cm}^{3}$ the implantation energy of $2.75 \mathrm{keV}$ corresponds to the depth of $500 \mathrm{~nm}$. In order to determine the thickness of the layers and the positron diffusion length, VEPFIT numerical packet [10] was used.

\section{Results}

In Fig. 1 X-ray diffraction measurements of ITO substrate on $\mathrm{Si}-\mathrm{Al}$ glass and of $\mathrm{TiO}_{2}$ layers annealed at three temperatures are shown. The sample annealed at $300^{\circ} \mathrm{C}$ does not show the presence of anatase, indicating an amorphous phase of $\mathrm{TiO}_{2}$. A similar amorphous phase is observed in samples deposited by vacuum deposition, see Fig. 2a. Both the sample annealed at $500^{\circ} \mathrm{C}$ and surprisingly that annealed at $700^{\circ} \mathrm{C}$ show the presence of anatase. However, in the latter sample a spur signal, probably due to some interlayer mixed phase arises (see Fig. 1d). The anatase phase is present also in samples deposited on $\mathrm{SnO}_{2}$ layers, see Fig. 3a.

Positron measurements substrates, see Fig. 4a, allow us to determine the values of the $S$-parameter for the two glasses: it amounts to 0.515 for sodium-silica glass and about 0.48 for alumina-silica glass. In the case of the $\mathrm{Al}-\mathrm{Si}$ glass, it is also possible to determine the $S$-parameter for the ITO layer -0.47 ; in the case of $\mathrm{Na}-\mathrm{Si}$ glass, the layer is too thin to be measured with positrons. The diffusion length for positrons in ITO layer is quite small — about $4 \mathrm{~nm}$; the depth of ITO layer as obtained from VEPFIT deconvolutions is $140 \mathrm{~nm}$ in all samples.

In the case of $\mathrm{Al}-\mathrm{Si}$ substrate, in positron data, we observe three well-distinct layers: all three samples (see Fig. $4 \mathrm{~b}$ ), the $S$-parameter converges to a similar bulk 

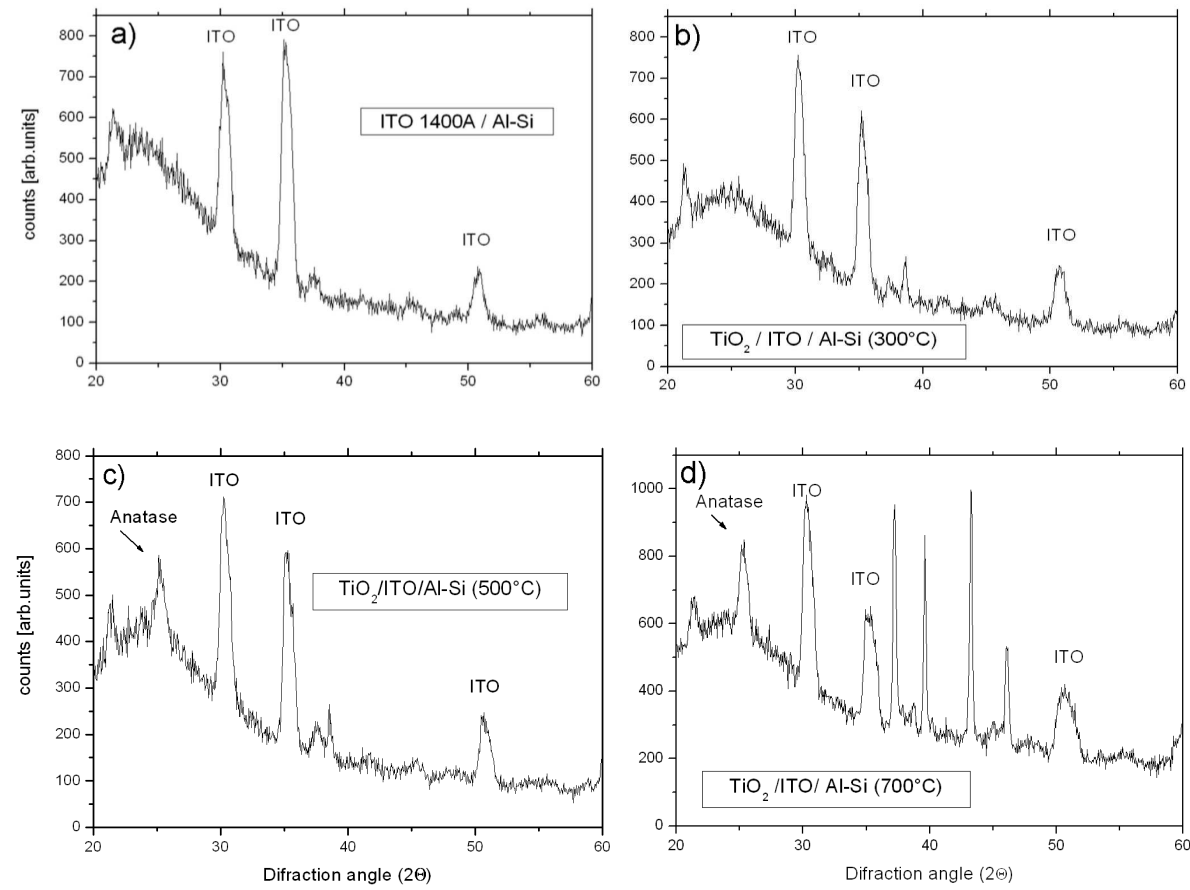

Fig. 1. XRD analysis of $\mathrm{TiO}_{2}(300 \mathrm{~nm}) / \mathrm{ITO}(140 \mathrm{~nm})$ layers on alumina-silica glasses. Peaks due to the anatase phase are well visible for sample annealed at $500^{\circ} \mathrm{C} \mathrm{(c)} \mathrm{and}$ $700^{\circ} \mathrm{C}(\mathrm{d})$ but not for the sample annealed at $300^{\circ} \mathrm{C}(\mathrm{b}) . \mathrm{XRD}$ of sample annealed at $700^{\circ} \mathrm{C}(\mathrm{d})$ shows additional, no-identified peaks, probably due to the mixing between the substrate glass and the ITO layer. XRD spectrum of solely ITO layer without $\mathrm{TiO}_{2}$ is shown for comparison (a).
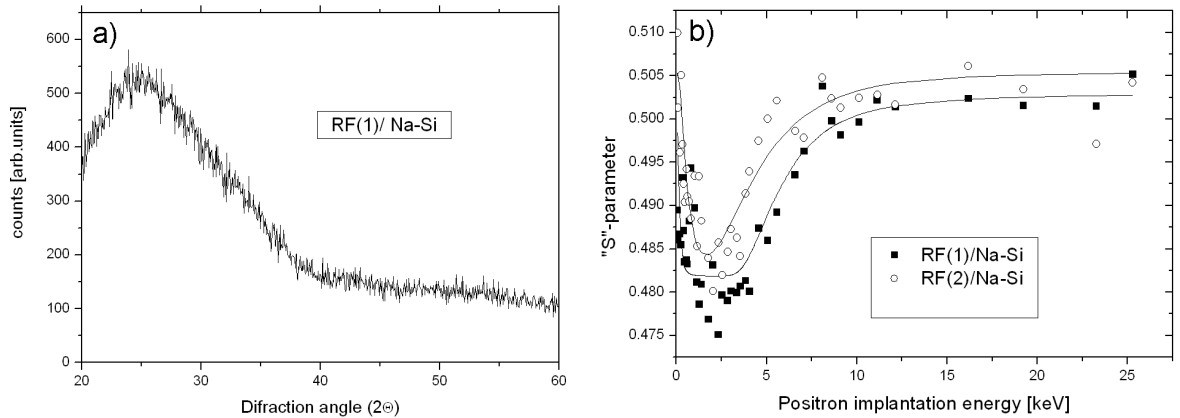

Fig. 2. X-ray diffraction (a) and positron-annihilation $S$-parameter (b) by $\mathrm{TiO}_{2}$ samples deposited on $\mathrm{Na}-\mathrm{Si}$ glass (without conducting oxide layer) by dc magnetron sputtering (the expected thickness of the layer is about $200 \mathrm{~nm}$ for sample no. 2 and $500 \mathrm{~nm}$ for sample no. 1). 
$S$-value, characteristic of the Al-Si glass. Minima in $S$ curves in Fig. 4b for the samples heated at $300^{\circ} \mathrm{C}$ and $700^{\circ} \mathrm{C}$ are shifted to higher energies than that of $500^{\circ} \mathrm{C}$ sample, indicating a thinner layer and/or lower density of $\mathrm{TiO}_{2}$ phase in the latter sample. On the other hand, the minimum for the $700^{\circ} \mathrm{C}$-sample is deeper, close to the value of pure ITO, and indicating lowered diffusion of positrons between $\mathrm{TiO}_{2}$ and ITO layers.

The $S$ values for $\mathrm{TiO}_{2}$ layers for samples in Fig. 4b fall from 0.495 in $300^{\circ} \mathrm{C}$ sample to 0.458 in $500^{\circ} \mathrm{C}$ and 0.467 in $700^{\circ} \mathrm{C}$ sample. This continuous lowering of the $S$-parameter would indicate a continuous change of the structure, towards a more compact one (from amorphous to anatase and rutile). The positron dif-
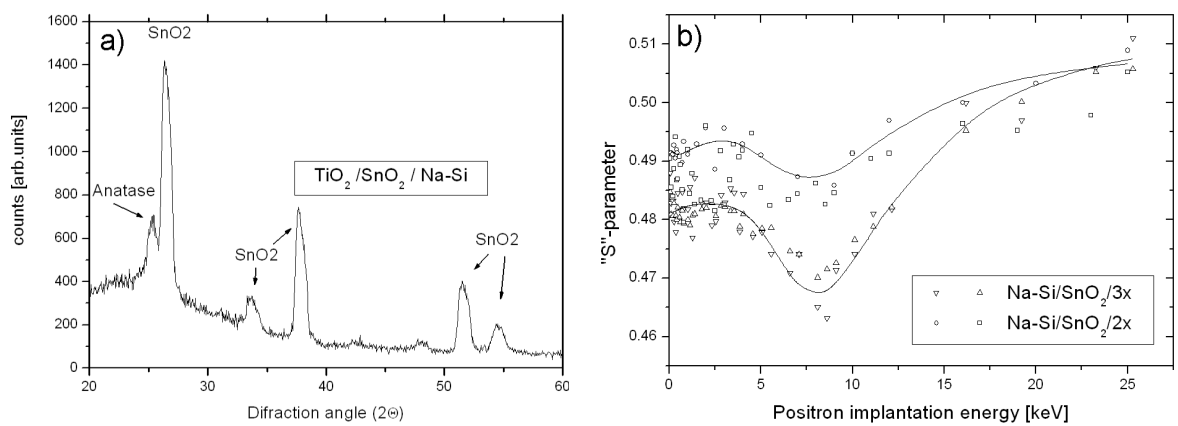

Fig. 3. X-ray diffraction (a) and positron-annihilation $S$-parameter (b) by sol-gel technique on $\mathrm{SnO}_{2}$-coated sodium-silica glasses (a triple layer in (a) and a double and a triple layer of $\mathrm{TiO}_{2}$ in (b)).
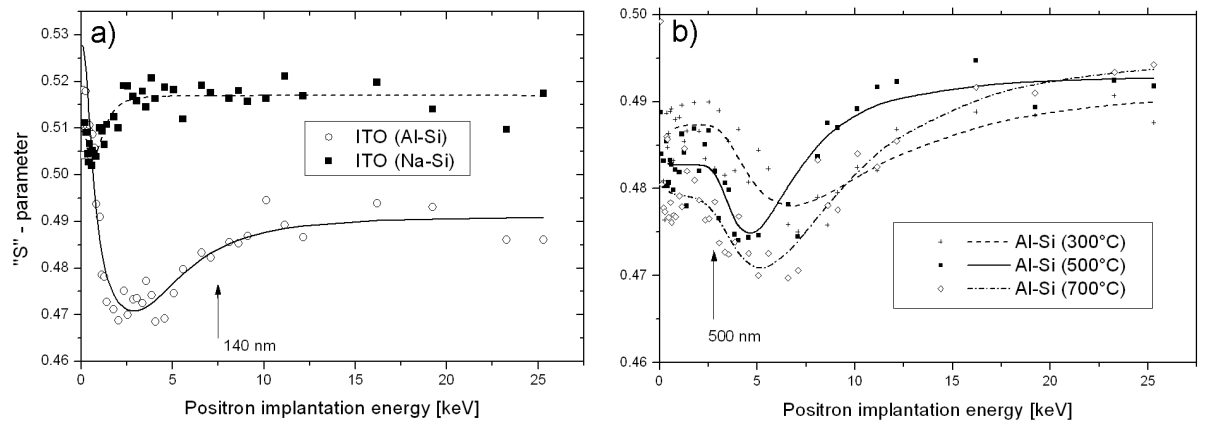

Fig. 4. Positron-annihilation $S$-parameter dependence on positron implantation energy for samples deposited by sol-gel technique on Sigma-Aldrich ITO-coated glasses. (a) $S$-parameter for "as-received glasses" - allowing to determine characteristic $S$ for the glass substrate and ITO layer. (b) Double $\mathrm{TiO}_{2}$ layers on alumina-silicate glasses, annealed at different temperatures. The arrow in (a) corresponds to the mean range of positrons of $140 \mathrm{~nm}$, as calculated for the layer density of $7 \mathrm{~g} / \mathrm{cm}^{3}$; in (b) - to the depth of $500 \mathrm{~nm}$, as calculated for $4 \mathrm{~g} / \mathrm{cm}^{3}$. 
fusion length in $\mathrm{TiO}_{2}$ layers is high, $140 \mathrm{~nm}$ for the $300^{\circ} \mathrm{C}$ sample and about $45 \mathrm{~nm}$ in $500^{\circ} \mathrm{C}$ and $700^{\circ} \mathrm{C}$ samples. This high diffusion length explains the high effectiveness of charge transfer from $\mathrm{TiO}_{2}$ to ITO, indispensable for photovoltaic processes.

Layers deposited on $\mathrm{SnO}_{2}$ show similar $S$-parameters to those deposited on ITO (cf. Fig. 3b). Layers deposited by sputtering of $\mathrm{Ti}$ in $\mathrm{O}_{2}$ atmosphere are different, as seen by positrons, from all other samples, showing a high value of $S$-parameter on surface. This would indicate the presence of numerous trapping centers.

In conclusion, both the presence and different types of $\mathrm{TiO}_{2}$ phases can be traced by positron-depth resolved annihilation and XRD techniques. Well-defined layers, of anatase on ITO, not intermixed with substrate, give the best photoelctrochemical performance [7].

\section{Acknowledgments}

We thank dr D. Pliszka for help in VEPFIT analysis and Miss M. Spagolla for help in positron measurements.

\section{References}

[1] T. Matsumoto, Y. Murakami, Y. Takasu, Chem. Lett. 49 348, 00 (20.)

[2] K. Madhysudan Reddy, Debanjan Guin, Sunkara V. Manorama, J. Mater. Res. 19, 2567 (2004).

[3] Weon-Pil Tai, Sol. En. Mater. Solar Cells 76, 65 (2003).

[4] Gang He, Qi Fang, Liqiang Zhu, Mao Liu, Lide Zhang, Chem.Phys. Lett. 395, 259 (2004).

[5] Peng Wang, S.M. Zakeeruddin, J.E. Moser, M.K. Nazeeruddin, T. Sekiguchi, M. Grätzel, Nature Mater. 2, 402 (2003).

[6] M. Grätzel, Nature 421, 586 (2003).

[7] E. Zomer, MSc. thesis, Trento University (2004).

[8] G.P. Karwasz, A. Zecca, R.S. Brusa, D. Pliszka, J. Alloys Comp. 382, 244 (2004).

[9] R.S. Brusa, G.P. Karwasz, M. Bettonte, A. Zecca, Appl. Surf. Sci. 116, 59 (1997).

[10] A. van Veen, H. Schut, J. de Vries, R.A. Hakvoort, M.R. Ijpma, in: AIP Conf. Proc., Positron Beams for Solids and Surfaces, Eds. P.J. Schultz, G.R. Massoumi, P.J. Simpson, Vol. 218, London (Ontario) 1990, p. 171. 